\title{
Determination of Binding Mode: Intercalation
}

This unit describes several techniques that can be used to establish the role of intercalation in the binding of small molecules to DNA. In very general terms, a molecule can be presumed to bind to DNA by intercalation between base pairs if it causes lengthening and unwinding of the DNA helix and undergoes changes in its spectral properties, such as DNA-induced hypochromism and quenching of its UV absorbance. DNA lengthening and unwinding can be determined from the change in viscosity of a solution of linear or plasmid DNA, respectively, upon addition of ligand (see Basic Protocols 1 and 2 and Alternate Protocols 1 and 2). Changes in the optical properties upon intercalation of the ligand can be monitored as described in Basic Protocol 3. A Support Protocol detailing the preparation of appropriately sized and purified DNA needed for Basic Protocols 1 and 3 and Alternate Protocol 1 is also included. If one of the above-mentioned criteria is not satisfied, then classical intercalation cannot be assumed. Ultimately, biochemical evidence for intercalation should be corroborated by nuclear magnetic resonance (NMR) or crystallographic studies.

Of critical importance to these binding mode experiments is knowledge of the thermodynamics of binding of the molecule to DNA. The determination of binding constants is presented in UNIT 8.2.

\section{DETERMINATION OF DNA LENGTHENING BY VISCOMETRY}

The mechanical properties of DNA require that the helix be lengthened to accommodate the positioning of a molecule between DNA base pairs. The simplest method to measure this lengthening is viscometry, as the viscosity of a DNA solution increases with the length of a DNA molecule. Using a capillary viscometer suspended in a constant-temperature water bath, the rate of flow of a solution of short DNA fragments is measured in the absence and presence of a candidate intercalator to determine the relative change in viscosity of the solution.

\section{Materials}

$10 \% \mathrm{HNO}_{3}$

$10 \mathrm{mM}$ buffer (Tris. Cl, HEPES, or other buffer) containing $1 \mathrm{mM}$ EDTA, $\mathrm{pH} 7$ (for TE buffer see APPENDIX 2A)

0.8 to $2.5 \mathrm{mM}$ (base pairs) sonicated S1 nuclease-treated calf thymus DNA of 200-bp average length, in above buffer (see Support Protocol)

Ligand of interest dissolved in above buffer

Semi-micro capillary viscometer (Cannon-Ubehold or Cannon-Manning semi-micro type 75, see Fig. 8.1.1)

0.4- $\mu \mathrm{m}$ membrane filtration apparatus (e.g., Millipore Ultrafree MC or Centricon filters)

Constant-temperature water bath, $25^{\circ} \pm 0.1^{\circ} \mathrm{C}$

Stopwatch $( \pm 0.01 \mathrm{sec})$ or Wescan fiber-optic detection unit and timer (Wescan Instruments)

Micropipettor with extension or extended microsyringe assembly (Hamilton or Stoelting) 


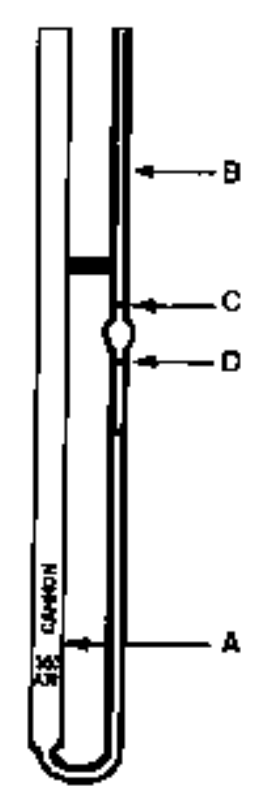

Figure 8.1.1 Cannon-Manning semi-micro viscometer. As described in Basic Protocol 1, solution is placed in tube $A$ and suction is applied to tube $B$ to draw solution above mark $C$. Flow time is determined from the time it takes for the meniscus to pass from mark $C$ to mark $D$.

NOTE: All solutions should be passed through a $0.4-\mu \mathrm{m}$ membrane filter to remove particulate matter that could clog the viscometer capillary and thus produce aberrant flow times.

\section{Determine buffer flow time}

1. Clean the viscometer overnight with $10 \% \mathrm{HNO}_{3}$, rinse thoroughly with deionized water, and dry prior to use. Place $1 \mathrm{~mL}$ of $10 \mathrm{mM}$ buffer in a semi-micro capillary viscometer (tube A in Fig. 8.1.1) and equilibrate to $25^{\circ} \mathrm{C}$ for $5 \mathrm{~min}$ in a constant-temperature water bath.

To conserve reagents, volumes as low as $750 \mu \mathrm{L}$ can be used in certain viscometers, such as the Cannon 75C15. Be sure to use the same volume in all determinations.

The viscometer should remain immersed in the water bath at all times.

2. Apply gentle suction to the other end of the viscometer (tube B in Fig. 8.1.1) with a pipet bulb and draw the buffer into the arm with the capillary until the meniscus lies above the upper marking (etched line) on the viscometer (mark $\mathrm{C}$ in Fig. 8.1.1).

3. Release the suction and start the stopwatch when the meniscus reaches the upper marking (mark C). Stop the stopwatch when the meniscus reaches the lower marking (mark D).

Alternatively, the fiber-optic detection unit can be used to automatically determine flow times.

4. Perform several repetitions of the flow-time determination until the flow times fall within $\pm 0.5 \mathrm{sec}$. Calculate the average flow time for at least three determinations.

5. Remove the buffer completely from the viscometer using a micropipettor with an extension or a long microsyringe to withdraw the remaining droplets.

Determination of Binding Mode: Intercalation
Each solution must be completely removed from the viscometer prior to the addition of the next solution to prevent dilution of the DNA or ligand concentration. 
6. Prepare $1 \mathrm{~mL}$ of sonicated, $\mathrm{S} 1$ nuclease-treated calf thymus DNA at $1 \mathrm{mM}$ base pairs in buffer.

7. Dispense the solution into the viscometer and equilibrate to $25^{\circ} \mathrm{C}$ in the water bath for $5 \mathrm{~min}$.

8. Determine flow times as described in steps 2 to 4 . Optimize the flow time by repeating this step with varying concentrations of DNA.

The flow time should vary between $70 \mathrm{sec}$ and $150 \mathrm{sec}$ depending on the particular viscometer used. The acceptable range of DNA concentrations is 0.5 to $2.5 \mathrm{mM}$ base pairs.

9. Prepare a 5- to 10-mL filtered stock of the final DNA solution.

This will avoid small changes in viscosity due to pipetting errors.

\section{Determine flow time without ligand}

10. Place $1 \mathrm{~mL}$ of the appropriate DNA solution into the viscometer and equilibrate to $25^{\circ} \mathrm{C}$.

11. Perform several repetitions of the flow-time determination (steps 2 to 4 ) until the flow times fall within $\pm 0.5 \mathrm{sec}$. Calculate the average flow time for at least three determinations.

Determine flow time in the presence of ligand

12. Add a small, filtered aliquot of the ligand dissolved in buffer ( 1 to $2 \mu \mathrm{L}$ ) to the DNA solution in the viscometer and mix the solution by repeated gentle pipetting or by gently bubbling nitrogen through the solution. Equilibrate to $25^{\circ} \mathrm{C}$ for $5 \mathrm{~min}$.

It is best to start with a ligand concentration that results in 3 to 10 bound ligand molecules per 100 base pairs of DNA. This concentration can be calculated from the binding constant determined as described in UNIT 8.2. Alternatively, a broad range of ligand concentrations can be examined; however, this is time consuming.

Particulate matter should be removed from the ligand solution by filtration.

13. Determine the average flow time as in steps 2 to 4 .

14. Repeat steps 12 and 13 until the total added volume of ligand is no more than $15 \mu \mathrm{L}$.

The small dilution of DNA by added ligand will be taken into account in the calculation of relative viscosities described shortly.

15. If additional ligand concentrations are required, rinse the viscometer with deionized water, dry, and start with a more concentrated ligand stock and a fresh 1-mL volume of DNA solution. Repeat steps 10 and 11, and use this flow time in subsequent calculations of relative viscosity changes with the new ligand concentrations.

\section{Calculate relative viscosities and analyze data}

16. Calculate the specific viscosity of the DNA solution without added ligand $\left(\eta_{0}\right)$ using the flow times of buffer without $\left(t_{0}\right)$ and with $(t)$ DNA and the equation $\eta_{0}=\left(t-t_{0}\right) / t_{0}$.

17. Calculate the specific viscosity of the DNA solution with added ligand $(\eta)$ using the flow times of buffer alone $\left(t_{0}\right)$ and buffer with DNA plus ligand $\left(t_{1}\right)$ and the equation $\eta=\left(t_{1}-t_{0}\right) / t_{0}$. Correct the flow times of samples diluted by serial addition of ligand by multiplying the value by the degree of dilution.

18. Plot $\left(\eta / \eta_{0}\right)^{1 / 3}$, which is the cubed root of the relative viscosity, as a function of the moles of ligand bound per base pair of DNA $(r)$. 
ALTERNATE PROTOCOL 1

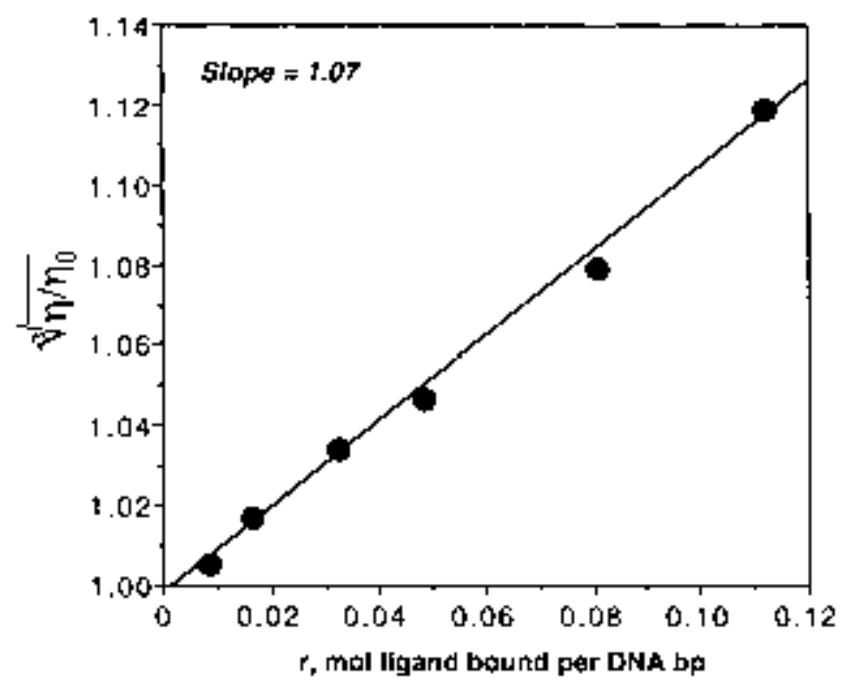

Figure 8.1.2 Viscometry data for ethidium bromide binding to sonicated calf thymus DNA. According to the theory of Cohen and Eisenberg (1969), a plot of the cubed root of the specific relative viscosity versus $r$ should yield a slope of 1 for a classical intercalator. The slope of 1.07 determined for ethidium bromide is in reasonable agreement with this value.

The latter value is calculated from the binding constant determined in UNIT 8.2.

See Commentary for a discussion of the interpretation of this plot in terms of intercalation. An example of such a plot for the binding of ethidium bromide is shown in Figure 8.1.2.

\section{DETERMINATION OF DNA LENGTHENING BY VISCOMETRY FOR LIGANDS SOLUBLE IN ORGANIC SOLVENTS}

DNA-binding ligands are often water insoluble, which necessitates addition of small amounts of organic solvent to DNA solutions. However, organic solvents significantly affect the viscosity of the DNA solution. To avoid solvent anomalies, viscosity studies, in this case, must be performed at a constant concentration of organic solvent and each ligand concentration must be assessed independent of other concentrations; serial addition of aliquots of the ligand solution will affect the total solvent concentration and thus the viscosity. Additionally, some organic solvents have a tendency to produce air bubbles in aqueous solutions, which will produce anomalous flow times. This problem is solved by degassing the solutions prior to viscometric studies; volatile solvents should be added after the buffer is degassed.

\section{Additional Materials (also see Basic Protocol 1)}

Ligand of interest dissolved in an organic solvent that is miscible with water Organic solvent

Microcentrifuge tubes

Small vacuum desiccator with water aspirator

Micro stir bars to fit in microcentrifuge tubes

Magnetic stirring plate

\section{Degas solutions}

1. In microcentrifuge tubes, prepare 1-mL solutions of buffer, DNA, and DNA with each concentration of ligand to be tested, making sure that each solution has the same final concentration of organic solvent.
Determination of

Binding Mode: Intercalation 
If a volatile solvent must be used, degas the aqueous solutions first (steps 1 to 3) and then add solvent (with or without ligand) after degassing.

The solvent concentration should be the same as that used in the determination of the DNA binding constant for the ligand (UNIT 8.2). This permits calculation of the proportion of DNA-bound ligand during the viscosity measurements. In addition, the DNA and organic solvent concentrations in the samples must be carefully controlled to ensure meaningful results. This can be accomplished by preparing one large DNA stock solution and dividing it into aliquots for each ligand concentration, followed by addition of ligand in solvent. Positive-displacement pipettors can be used to ensure that precise quantities of organic solvent are delivered to the solutions.

2. Place a micro stir bar in each tube and place the tubes, with lids open, upright in a small beaker with a piece of tissue to support the tubes.

3. Place the beaker in a vacuum desiccator atop a magnetic stirring plate and, while stirring, apply a vacuum for 5 to $10 \mathrm{~min}$.

A water aspirator will supply adequate vacuum to degas the solutions. The solutions must be stirred to prevent bumping of the contents during evacuation.

\section{Determine flow times and analyze the viscosity data}

4. Optimize flow times for the DNA solution without ligand as described (see Basic Protocol 1, steps 6 to 9).

5. Determine flow times of buffer, DNA alone, and DNA with ligand as described (see Basic Protocol 1, steps 1 to 5 and 10 to 15), but replace each solution with the next higher ligand concentration instead of adding additional ligand to increase the concentration.

There is likely to be greater scatter in the viscosity data with this protocol due to the necessity of using separate DNA solutions for each ligand concentration. This problem is controlled by performing multiple determinations for each ligand concentration.

6. Calculate relative viscosities as described (see Basic Protocol 1, steps 16 to 18).

\section{ASSESSMENT OF DNA UNWINDING BY PLASMID VISCOMETRY}

The second hallmark of intercalation is unwinding of the DNA helix to accommodate the intercalating ligand. Among the several techniques available to assess helical unwinding, plasmid viscometry is perhaps the easiest. The technique is based on changes in DNA topology, and thus the viscosity of the DNA solution, when an intercalator binds to closed circular plasmid DNA. Knowledge of the DNA binding constant (UNIT 8.2) under the conditions of the plasmid viscometry allows direct calculation of the angle of unwinding for each bound intercalator. The unwinding angle can also be calculated by comparison to ethidium bromide without knowledge of the binding constant. Both analyses are described below. Additionally, the same binding constant can be applied to all of the studies in this unit if identical buffer, solvent, and temperature conditions are employed.

\section{Materials}

DNA: Phage DNA M13mp, PM2, or $\varnothing X 174$; plasmids COL E1 or pBR325; or any similarly sized plasmid (5 to $7 \mathrm{kbp}$ ); each prepared by standard alkaline lysis (e.g., CPMB UNIT 1.7) or similar procedures, and suspended at $1 \mathrm{mg} / \mathrm{mL}$ in TE (APPENDIX 2A) or other buffer

$10 \mathrm{mM}$ buffer (Tris. Cl, HEPES, or other buffer) containing $1 \mathrm{mM}$ EDTA, pH 7 (for TE buffer see APPENDIX 2A)

Ligand of interest dissolved in above buffer $(\sim 1 \mathrm{mM})$

1 to $2 \mathrm{mM}$ ethidium bromide solution (see recipe) 
Semi-micro capillary viscometer (Cannon-Ubehold or Cannon-Manning semi-micro type 75, see Fig. 8.1.1)

0.4- $\mu \mathrm{m}$ membrane filtration apparatus (e.g., Millipore Ultrafree MC or Centricon filters)

Constant-temperature water bath, $25^{\circ} \pm 0.1^{\circ} \mathrm{C}$

Stopwatch $( \pm 0.01 \mathrm{sec})$ or Wescan fiber-optic detection unit and timer (Wescan Instruments)

Micropipettor with extension or extended microsyringe assembly (Hamilton or Stoelting)

CAUTION: Ethidium bromide is a mutagen and an environmental hazard. It should be handled carefully with gloves and disposed of properly. Methods of disposal may vary between institutions. Consult with the institution's environmental safety office for the preferred means of storage and disposal of ethidium bromide.

\section{Determine flow times}

1. Determine the average flow time for a $1-\mathrm{mL}$ solution of DNA at a concentration of 0.1 to $0.6 \mathrm{mM}$ nucleotides ( 30 to $200 \mu \mathrm{g} / \mathrm{mL}$ ) as described (see Basic Protocol 1, steps 6 to 11 ).

The choice of DNA concentrations depends on the dissociation constant of the ligand. For dissociation constants in the micromolar range, a DNA concentration 0.2 to $0.6 \mathrm{mM}$ (nucleotides) ensures virtually complete binding of the ligand, thus obviating the need to determine the quantity of free and bound ligand.

2. Add the ligand to the DNA solution in the viscometer in 5- to $10-\mu \mathrm{L}$ increments and mix the solution by repeated pipetting or by bubbling nitrogen through the solution.

The incremental addition of ligand to the DNA solution will produce minor alterations in the viscosity of the solution compared to the changes in DNA topology caused by ligand binding. However, the dilution must be accounted for in the calculation of the unwinding angle, which are based on actual ligand and DNA concentrations.

3. Following temperature equilibration, determine the average flow time (see Basic Protocol 1, steps 2 to 4 ) of the solution for each addition of ligand.

Additions of ligand should continue well past the point at which the viscosity reaches a maximum; this indicates complete relaxation of the supercoiled plasmid. Further addition of the intercalating ligand should result in positive supercoiling and a reduction in viscosity.

If there is a bell-shaped dependence of viscosity (flow time) on ligand concentration, then the ligand may be assumed to cause unwinding of the DNA helix.

If no change in viscosity is observed after ten aliquots of ligand are added, then the ligand either binds with low affinity or with a small unwinding angle (i.e., DNA unwinding is minimal); or, less likely, binds with very high affinity or with a very large unwinding angle (i.e., the first aliquot of ligand produced maximal positive supercoiling). To overcome this problem, increase (or decrease) the ligand concentration 5-fold and repeat steps 1-3 until a bell-shaped curve is obtained.

\section{Determine the unwinding angle}

With prior knowledge of the binding constant:

Determination of Binding Mode: Intercalation 4a. Repeat the flow-time determinations for a serial addition of ethidium bromide to a fresh 1-mL DNA solution and determine the concentration of ethidium bromide that produces maximal relaxation of the plasmid DNA (maximal flow time). 
Ethidium bromide serves as a standard for helical unwinding, with each bound molecule unwinding the helix by $\sim 26^{\circ}$. As a starting point, ethidium bromide should produce full relaxation and positive supercoiling over a concentration range of 10 to $40 \mu \mathrm{M}$ with a 6 to 7-kbp negatively supercoiled plasmid at $\sim 0.3 \mathrm{mM}$ base pairs concentration.

5a. Calculate the molar binding ratio ( $\mathrm{v}$; moles of bound ligand per mole of nucleotides) under conditions of maximal relaxation for both ethidium bromide and ligand. Calculate the concentration of bound ligand using the binding constant and equation for the neighbor exclusion model discussed in UNIT 8.2.

6a. Calculate the unwinding angle (relative to ethidium bromide) from the equation $\varnothing_{\mathrm{L}}$ $=\varnothing_{\mathrm{Et}}\left(v_{\mathrm{Et}} / v_{\mathrm{L}}\right)$, where $\varnothing_{\mathrm{L}}$ is the unwinding angle for the ligand, $\varnothing_{\mathrm{Et}}$ is the known $26^{\circ}$ unwinding angle for ethidium bromide, and $v_{\mathrm{Et}}$ and $v_{\mathrm{L}}$ are the molar binding ratios for ethidium bromide and ligand, respectively, at concentrations producing maximal plasmid relaxation.

Without prior knowledge of the binding constant:

4b. Determine the concentration of ethidium bromide and ligand that produce maximal relaxation (maximal flow times) for four to five different DNA concentrations covering a four- to five-fold range (e.g., 0.5 to $2.5 \mathrm{mM}$ nucleotides).

5b. Plot the total concentration of ligand $\left(C_{\mathrm{T}}\right)$ versus the total DNA concentration $\left(N_{\mathrm{T}}\right)$ according to the equation $C_{\mathrm{T}}=\mathrm{v} N_{\mathrm{T}}+C_{\mathrm{F}}$, where the slope (v) is the molar binding ratio (moles of ligand bound per mole of nucleotides) and the $y$ intercept $\left(C_{\mathrm{F}}\right)$ is the concentration of free ligand.

6b. Calculate the unwinding angle (relative to ethidium bromide) from the equation: $\varnothing_{\mathrm{L}}$ $=\varnothing_{\mathrm{Et}}\left(v_{\mathrm{Et}} / v_{\mathrm{L}}\right)$, where $\varnothing_{\mathrm{L}}$ is the unwinding angle for the ligand, $\varnothing_{\mathrm{Et}}$ is the known $26^{\circ}$ unwinding angle for ethidium bromide, and $v_{\mathrm{Et}}$ and $\mathrm{v}_{\mathrm{L}}$ are the molar binding ratios determined from the slopes of the plots in step $5 b$.

\section{ASSESSMENT OF DNA UNWINDING BY PLASMID VISCOMETRY FOR LIGANDS SOLUBLE IN ORGANIC SOLVENTS}

The problems associated with studying ligands in the presence of organic solvents are identical to those discussed in Alternate Protocol 1 for DNA lengthening determined by viscometry. To avoid changes in organic solvent concentration associated with incremental addition of a ligand dissolved in the solvent, the viscosity studies must be performed at a constant concentration of organic solvent and each ligand concentration must be assessed independent of other concentrations. The materials and procedures for plasmid viscometric studies with ligands in organic solvent are exactly as described earlier. The flow time for each ligand concentration must be determined in a fresh DNA solution. Large quantities of DNA $(\sim 10 \mathrm{mg})$ are required for determination of the unwinding angle if the binding constant is not known because of the need to perform flow-time determinations for five to ten ligand and ethidium bromide concentrations at four to five different DNA concentrations.

\section{ASSESSMENT OF CHANGES IN THE OPTICAL PROPERTIES OF LIGANDS UPON BINDING TO DNA}

The third criterion for intercalative DNA binding is a change in the optical properties of the DNA-bound chromophore. The UV/visible absorbance of classical DNA intercalators is typically reduced by $40 \%$ to $60 \%$ when the chromophore inserts between DNA base pairs. Furthermore, there is often a shift in the absorbance maximum to longer wavelengths (i.e., a red shift) as the chromophore interacts with adjacent DNA bases. The

BASIC PROTOCOL 3

Nucleic Acid Binding Molecules 
following protocol assumes that the molar extinction (i.e., extinction coefficient) for the ligand can be determined and that the absorbance maximum $\left(\lambda_{\max }\right)$ of the ligand is significantly different from that of DNA $(>300 \mathrm{~nm})$.

\section{Materials}

Sonicated, S1 nuclease-treated calf thymus DNA (see Support Protocol)

$10 \mathrm{mM}$ buffer (Tris.Cl, HEPES, or other buffer) containing 1 mM EDTA, pH 7

(for TE buffer see APPENDIX 2A)

Ligand of interest dissolved in above buffer

Digital or double-beam UV/visible spectrophotometer capable of recording absorbance spectra

\section{Determine extinction coefficient of ligand in the absence of DNA}

1. Prepare five $1-\mathrm{mL}$ solutions of ligand at 1,3,10,30, and $100 \mu \mathrm{M}$ in the desired buffer.

Since the molar extinction varies as a function of factors such as ionic strength and $\mathrm{pH}$, these studies should be performed in the same buffer used in the viscometric studies and in the binding constant studies described in UNIT 8.2.

The wide range of ligand concentrations ensures that several concentrations will produce an absorbance value between 0.01 and 1 absorbance unit (AU).

2. Blank a spectrophotometer against the buffer either digitally or by placing the buffer in one of the compartments of a double-beam instrument.

3. Place a cuvette containing the first ligand solution into the spectrophotometer and record the spectrum from 200 to $800 \mathrm{~nm}$.

4. Record spectra for each of the ligand concentrations.

5. For spectra containing absorbance peaks in the range of 0.01 to $1 \mathrm{AU}$, note the wavelength and exact absorbance for a major peak or shoulder that lies above the absorbance of DNA (>300 nm).

6. Calculate the extinction coefficient $(\varepsilon)$ at this wavelength from the Beer-Lambert law: $A=\varepsilon l c$, where $A$ is the absorbance value, $l$ is the cuvette path length in $\mathrm{cm}$, and $c$ is the molar ligand concentration.

The extinction coefficient is valid only under the conditions used in its determination (e.g., buffer type, $p H$, ionic strength, temperature, and so on). The coefficient should be calculated from triplicate determinations of at least three different concentrations.

\section{Determine extinction coefficient of ligand in the presence of DNA}

7. Prepare four solutions each containing (1) a ligand concentration that will produce an absorbance of $\sim 0.2$ to 0.3 and (2) a DNA concentration (nucleotides) that is 3-, 10-, 30-, and 100-fold greater than the ligand concentration. Also prepare the same DNA solutions without ligand.

It is important to use S1 nuclease-treated DNA to avoid possible problems with spectral changes upon binding to single-stranded DNA.

8. Blank the spectrophotometer against one of the DNA solutions without ligand.

9. Record the absorbance spectrum of the ligand-containing solution with the same DNA concentration.

10. Repeat steps 8 and 9 for the other DNA concentrations. 
11. At the wavelength used for determining the extinction coefficient of unbound ligand in step 6, plot the absorbance for each ligand-containing solution versus the DNA concentration (in nucleotides) and determine the minimum absorbance value.

As the DNA concentration increases, the ligand absorbance should decrease to a minimum value indicative of complete ligand binding. There should be at least two DNA concentrations that produce the minimum absorbance value. If not, repeat steps 8 and 9 with a higher DNA concentration.

12. Use the minimum absorbance value to calculate the extinction coefficient for the DNA-bound ligand, as in step 6.

For a ligand with an association constant greater than $\sim 10^{4} \mathrm{M}^{-1}$, a 100-fold excess of DNA should result in the minimum absorbance indicative of complete ligand binding

Determine change in absorbance with DNA

13. Calculate the ratio of extinction coefficients in the absence and presence of DNA.

A classical intercalator will typically experience a $40 \%$ to $60 \%$ reduction in absorbance upon binding to DNA.

A shift in absorbance maximum of the ligand upon binding to DNA can be calculated by obtaining the absorbance spectrum of the ligand without DNA and in the presence of enough DNA to cause complete binding of the ligand.

\section{PREPARATION OF GENOMIC DNA FRAGMENTS FOR VISCOMETRY}

To avoid possible complications from ligand-induced changes in DNA flexibility, the viscometry studies in Basic Protocol 1 and Alternate Protocol 1 should be performed with DNA fragments roughly 200 to $250 \mathrm{bp}$ long. DNA of this length can be prepared by sonication of calf thymus DNA and size fractionation by gel-filtration chromatography. This protocol is also used to prepare DNA needed for the optical studies in Basic Protocol 3.

\section{Materials}

Calf thymus DNA (sodium salt)

Phosphate/EDTA buffer: $50 \mathrm{mM}$ sodium phosphate with $1 \mathrm{mM}$ EDTA, pH 7

Nitrogen gas

Gel loading buffer (APPENDIX 2A)

$1 \%(\mathrm{w} / \mathrm{v})$ agarose gel in TBE buffer

TBE buffer (APPENDIX 2A)

DNA size markers, 100 to 1000 bp (e.g., HaeIII-digested $\varnothing X 174$ DNA)

$10 \mathrm{mM}$ sodium acetate, $\mathrm{pH} 5 / 100 \mathrm{mM} \mathrm{NaCl} / 30 \mu \mathrm{M} \mathrm{ZnCl}_{2}$

S1 nuclease

Buffered phenol or 1:1 (v/v) phenol/chloroform (APPENDIX 2A)

$3 \mathrm{M}$ sodium acetate, $\mathrm{pH} 7$

$100 \%, 95 \%$, and $70 \%(\mathrm{v} / \mathrm{v})$ ethanol

TE buffer, pH 7.5 (APPENDIX 2A)

$10 \mathrm{mg} / \mathrm{mL}$ DNase-free RNase A (see recipe)

$20 \mathrm{mg} / \mathrm{mL}$ proteinase $\mathrm{K}$ in water (store in single-use aliquots at $-20^{\circ} \mathrm{C}$ )

24:1 (v/v) chloroform/isoamyl alcohol

$1 \mu \mathrm{g} / \mathrm{mL}$ ethidium bromide solution (see recipe)

Sonicator (e.g., Branson model 450)

3000- to 10,000-MWCO dialysis tubing

$3 \times 60-\mathrm{cm}$ column of Sepharose 4B or Sephacryl C-500-HR 
UV transilluminator

Additional reagents and equipment for agarose gel electrophoresis (e.g., CPMB UNIT $2.5 A$ ) and phenol/chloroform extraction (APPENDIX 2A)

\section{Sonicate DNA to produce short fragments}

1. Dissolve $100 \mathrm{mg}$ calf thymus DNA in $50 \mathrm{~mL}$ phosphate/EDTA buffer by stirring overnight at $4^{\circ} \mathrm{C}$.

2. Place the beaker containing the DNA solution on ice and gently bubble nitrogen through the solution for 5 min to remove oxygen.

The presence of nitrogen and removal of oxygen reduces the size of DNA fragments generated in subsequent sonication.

\section{For lengthening/unwinding studies:}

3. Sonicate the DNA for a total of $30 \mathrm{~min}$ in 5-min intervals at full power using the 0.5-in. end of a disrupter horn (for a Branson model 450 or similar sonicator) with 5 -min cooling periods between sonication periods. Gently bubble nitrogen through the solution during the cooling periods to remove oxygen.

For smaller volume $(<50 \mathrm{~mL})$, a microprobe sonicator tip can be used. However, to avoid damage to the probe, the energy setting must be reduced according to the manufacturer's specifications.

For the spectral studies of Basic Protocol 3, sonicate as in step 3 but reduce the time from 30 min to 10 to 15 min and proceed with step 6.

4. Assess the size of DNA fragments by removing $1 \mu \mathrm{g}$ of DNA from the sonication mixture, mixing with gel loading buffer, and resolving the DNA on a $1 \%$ agarose gel in TBE buffer until the bromophenol blue dye has migrated approximately one-half the length of the gel. Include a lane of DNA size markers covering the range of 100 to $1000 \mathrm{bp}$.

This ensures that an adequate quantity of 200- to 250-bp DNA fragments is present in the mixture of sheared DNA fragments.

5. If the fragment sizes are too large, sonicate the mixture for another 10 to $15 \mathrm{~min}$ and repeat the gel analysis.

\section{Remove single-stranded DNA:}

6. Dialyze the DNA three times against $4 \mathrm{~L}$ (each time) of $10 \mathrm{mM}$ sodium acetate, $\mathrm{pH}$ $5 / 100 \mathrm{mM} \mathrm{NaCl} / 30 \mu \mathrm{M} \mathrm{ZnCl}_{2}$ at $4^{\circ} \mathrm{C}$. Use 3000 - to $10,000-\mathrm{MWCO}$ dialysis tubing and perform at least one of the dialysis steps overnight.

7. Digest the single-stranded DNA with S1 nuclease (20 IU) $1 \mathrm{hr}$ at $37^{\circ} \mathrm{C}$. Extract the DNA several times with phenol and chloroform (see APPENDIX 2A).

8. Add $3 \mathrm{M}$ sodium acetate to $0.3 \mathrm{M}$ and 2 vol of $100 \%$ ethanol to precipitate. Centrifuge $15 \mathrm{~min}$ at $16,000 \times g$. Wash the DNA twice with $70 \%$ ethanol and once with $95 \%$ ethanol.

9. Dry the DNA either by vacuum centrifugation or by overnight evaporation on a bench top. Redissolve the dried DNA pellet in $50 \mathrm{~mL}$ TE buffer and proceed with step 7.

The dialysis can be performed after the sonication step. 
10. Remove the DNA from the dialysis tubing and add sodium acetate to $300 \mathrm{mM}$ followed by DNase-free RNase to $0.1 \mathrm{mg} / \mathrm{mL}$. Incubate $1 \mathrm{hr}$ at $37^{\circ} \mathrm{C}$.

11. Add proteinase $\mathrm{K}$ to $0.1 \mathrm{mg} / \mathrm{mL}$ and incubate $2 \mathrm{hr}$ at $37^{\circ} \mathrm{C}$.

12. Extract the solution four times with an equal volume of buffered phenol or $1: 1(\mathrm{v} / \mathrm{v})$ phenol/chloroform to remove proteins (APPENDIX 2A), and twice with 24:1 (v/v) chloroform/isoamyl alcohol to remove residual phenol.

13. Precipitate the DNA by adding 2 vol of $100 \%$ ethanol and centrifuging $15 \mathrm{~min}$ at $16,000 \times g, 4^{\circ} \mathrm{C}$.

14. Wash the DNA twice with $70 \%$ ethanol and once with $95 \%$ ethanol. Dry the DNA either by vacuum centrifugation or by overnight evaporation on a bench top.

\section{Size fractionate DNA}

15. Redissolve the DNA in phosphate/EDTA buffer at $4 \mathrm{mg} / \mathrm{mL}$ and apply half the solution to a $3 \times 60-\mathrm{cm}$ Sepharose $4 \mathrm{~B}$ or Sephacryl S-500-HR gel-filtration column to resolve the DNA fragments by size.

The other half of the DNA solution can be stored at $-20^{\circ} \mathrm{C}$ for later chromatographic purification.

The most convenient means to monitor the elution of DNA from the column is to use a complete liquid chromatographic system with a peristaltic pump, UV detector (254 $\mathrm{nm}$ ), chart recorder, and fraction collector.

16. Mix a 5- to $10-\mu \mathrm{L}$ aliquot of each fraction with gel loading buffer and resolve the DNA on a $1 \%$ agarose gel as in step 4 a.

The aliquot should contain 50 to $300 \mathrm{ng}$ of DNA based on absorbance at $260 \mathrm{~nm}$, assuming that $1 A_{260}=50 \mu \mathrm{g} / \mathrm{mL} D N A$.

17. Stain the gel with $1 \mu \mathrm{g} / \mathrm{mL}$ ethidium bromide solution and visualize the DNA fragments by UV illumination.

CAUTION: Ethidium bromide is a mutagen and environmental hazard. It should be handled carefully with gloves and disposed of properly. Methods of disposal may vary between institutions. Consult with the institution's environmental safety office for the preferred means of storage and disposal.

18. Identify the fractions containing DNA with an average size of $\sim 200 \mathrm{bp}$, pool these fractions, and dialyze the solution three times against $4 \mathrm{~L}$ of TE buffer at $4{ }^{\circ} \mathrm{C}$ with at least one overnight dialysis step.

19. Add 0.1 vol of $3 \mathrm{M}$ sodium acetate and precipitate the DNA with 2 vol of $100 \%$ ethanol by centrifuging $30 \mathrm{~min}$ at $16,000 \times g, 4^{\circ} \mathrm{C}$.

20. Wash and dry the pellet as in step 14 .

21. Dissolve the DNA in the desired buffer (see Basic Protocol 1 and Basic Protocol 3) at $3 \mathrm{mg} / \mathrm{mL}$ and store at $-20^{\circ} \mathrm{C}$.

The DNA can be stored several months at $-20^{\circ} \mathrm{C}$. If the DNA is to be kept for long periods, it can be stored in screw-cap tubes at $-80^{\circ} \mathrm{C}$ for at least a year. 


\section{REAGENTS AND SOLUTIONS}

Use deionized water in all recipes and protocol steps. For common stock solutions, see APPENDIX 2A; for suppliers, see SUPPLIERS APPENDIX.

\section{DNase-free RNase A, $10 \mathrm{mg} / \mathrm{mL}$}

Dissolve DNase-free RNase A in TE buffer (APPENDIX 2A) at $1 \mathrm{mg} / \mathrm{mL}$ and boil 10 to $30 \mathrm{~min}$. Store in aliquots at $-20^{\circ} \mathrm{C}$ to prevent microbial growth. For additional details on this enzyme, see CPMB UNIT 3.13 .

\section{Ethidium bromide solution, 1 to $10 \mathrm{mg} / \mathrm{mL}$}

Prepare a 1 to $10 \mathrm{mg} / \mathrm{mL}$ stock solution of ethidium bromide in water. Determine the exact concentration of ethidium bromide in this crude stock by measuring its absorbance at $480 \mathrm{~nm}$ and using the molar extinction coefficient $\left(\varepsilon_{480}\right)=5600$ $\mathrm{M}^{-1} \mathrm{~cm}^{-1}$. Store for up to 6 months at $4^{\circ} \mathrm{C}$ protected from light. For assessment of DNA unwinding (see Basic Protocol 2), dilute stock to 1 to $2 \mathrm{mM}$ in the desired buffer. For staining agarose gels (see Support Protocol), dilute to $1 \mu \mathrm{g} / \mathrm{mL}$ in TBE buffer (APPENDIX 2A).

\section{COMMENTARY}

\section{Background Information}

The three sets of experiments presented in this unit are designed to define the ability of a DNA-binding ligand to intercalate between the base pairs of DNA. If a ligand increases the viscosity of a solution of linear DNA fragments (Lerman, 1961; Waring, 1970), produces a bellshaped viscosity profile with plasmid DNA (Révet et al., 1971), and undergoes DNA-induced quenching of its absorbance, then it can be presumed to bind to DNA by intercalation. Alone, the individual observations are insufficient to establish intercalation since there are exceptions to each. For example, cisplatin, a DNA cross-linker that binds to the N7 position of guanine, and irehdiamine, a steroidal groove-binder, both unwind supercoiled plasmid DNA (Saucier 1977; Cohen et al., 1979), but neither causes an increase in the viscosity of a DNA solution. The reader is referred to the work of Satyanarayana et al. (1993) for a rigorous comparison of the viscometric and spectral behaviors of several groove binders and intercalators. This biophysical evidence for intercalation is best corroborated by NMR or $\mathrm{X}$-ray crystallographic studies.

\section{Critical Parameters}

Several parameters must be controlled to avoid erroneous results. First, the viscometer should be cleaned after each use by overnight soaking in $10 \%$ to $50 \%$ nitric acid, followed by thorough rinsing with deionized water and drying. Particulate matter present in all of the solutions should be removed by filtration through a $\geq 0.4-\mu \mathrm{m}$ filter.
Second, the temperature, ionic composition, $\mathrm{pH}$, and concentration of organic solvents must be precisely controlled in viscosity studies. Small changes in organic solvent concentration, for example, can significantly alter flow times in the viscometer. These same conditions must be employed for the determination of binding constants discussed in UNIT 8.2, since the thermodynamics of ligand binding vary according to the properties of the solution.

Third, it is important to check for changes in flow time of the buffer and control DNA solutions regularly throughout the viscometric studies. This ensures that there are no anomalies caused by residual solvents or components sticking to the walls of the viscometer capillary.

Finally, the length of the linear DNA fragments must be short enough to avoid problems arising from ligand-induced changes in the flexibility of the DNA. The use of $\sim 200$-bp DNA fragments, roughly the persistence length of DNA, prevents problems with flexibility. Significantly shorter fragments $(<50 \mathrm{bp})$ will produce unacceptably short flow times.

\section{Troubleshooting}

The most likely cause of highly variable flow times is a dirty or clogged viscometer. Regular cleaning of the viscometer and filtration of the solutions will prevent this problem. The presence of small air bubbles in the viscometer capillary can be avoided by degassing the solutions, especially those containing nonvolatile organic solvents. Care must be taken to avoid precipitation of the DNA fragments that can be caused by extremely high concentrations 
of some ligands as indicated by visible precipitates or a sudden decrease in flow time. Furthermore, high concentrations of water-insoluble ligands can result in aggregation and precipitation of the ligand, which may also create problems. One way to check for viscosity changes due to ligand insolubility is to perform flow-time measurements with high concentrations of the ligand in buffer alone.

Although flow times will depend on the type of viscometer used, excessively long flow times ( $>180 \mathrm{sec}$ ) can be avoided by reducing the DNA concentration.

\section{Anticipated Results}

The results of the plasmid viscosity experiments are self explanatory: if the viscosity of the DNA solution increases and then decreases in a bell-shaped curve as a function of ligand concentration, then the ligand can be presumed to unwind the DNA helix. For the DNA lengthening studies, the theory of Cohen and Eisenberg (1969) predicts that a plot of $\left(\eta / \eta_{0}\right)^{1 / 3}$ versus $r$ (moles of ligand bound per mole of DNA base pairs) will give a slope $\approx 1$ for a "classical" intercalator (for example, see Fig. 8.1.2). This result is based on the predicted 3.4- $\AA$ increase in the length of the DNA helix when an intercalator is positioned between DNA base pairs. Most classical intercalators produce a slope lying between 0.5 and 1 in such a plot (Wilson and Jones, 1982), while "classical" groove binders such as Hoechst 33258 produce a slope of zero (Satyanarayana et al., 1993).

With regard to changes in ligand absorbance upon binding to DNA, the results can be highly variable. Classical intercalators, as well as many groove-binding ligands, will show a reduced absorbance of light when bound to DNA. However, a shift to longer wavelengths does not always accompany intercalation, as illustrated by the binding of the intercalating enediyne esperamicin A1 to DNA (Yu et al., 1994).

\section{Time Considerations}

The time to complete the viscosity studies is highly variable and depends on the number of ligand concentrations studied, the need for organic solvents, and the experience of the researcher. At least 1 week of work should be anticipated to complete each protocol. Although the preparation of DNA fragments and plasmid DNA will require additional time, sufficiently large quantities of these reagents can be prepared at one time for use in many different studies.

\section{Literature Cited}

Cohen, G. and Eisenberg, H. 1969. Viscosity and sedimentation study of sonicated DNA-proflavine complexes. Biopolymers 8:45-55.

Cohen, G.L., Bauer, W.R., Barton, J.K., and Lippard, S.J. 1979. Binding of cis- and trans-dichlorodiammineplatinum(II) to DNA: Evidence for unwinding and shortening of the double helix. Science 203:1014-1016.

Lerman, L.S. 1961. Structural considerations in the interaction of DNA and acridines. J. Mol. Biol. 3:18-30.

Révet, B.M., Schmir, M., and Vinograd, J. 1971. Direct determination of the superhelix density of closed circular DNA by viscometric titration. Nature 229:10-13.

Satyanarayana, S., Dabrowiak, J.C., and Chaires, J.B. 1993. Tris(phenanthroline)ruthenium(II) enantiomer interactions with DNA: Mode and specificity of binding. Biochemistry 32:25732584.

Saucier, J.-M. 1977. Physicochemical studies on the interaction of irehdiamine A with bihelical DNA. Biochemistry 16:5879-5889.

Waring, M. 1970. Variation in the supercoils in closed circular DNA by binding of antibiotics and drugs: Evidence for molecular models involving intercalation. J. Mol. Biol. 54:247-279.

Wilson, W.D. and Jones, R.L. 1982. Intercalation in biological systems. In Intercalation Chemistry (M.S. Whittingham and A.J. Jacobson, eds.) pp. 445-501. Academic Press, New York.

Yu, L., Golik, J., Harrison, R., and Dedon, P. 1994. The deoxyfucose-anthranilate of esperamicin A1 confers intercalative DNA binding and causes a switch in the chemistry of bistranded DNA lesions. J. Am. Chem. Soc. 116:9733-9738.

Contributed by Peter C. Dedon

Massachusetts Institute of Technology

Cambridge, Massachusetts
Nucleic Acid Binding Molecules 